\title{
THE GIANT SEX CHROMOSOMES IN THE MAMMAL MICROTUS AGRESTIS
}

\author{
LEO SACHS \\ John Innes Horticultural Institution, Hertford
}

Received I3.X.52

\section{INTRODUCTION}

THE study of mammalian chromosomes, despite their importance, has been greatly neglected. This is in part due to the idea that they are unsuitable for a proper cytological study (e.g. White, 1949). The best mammalian chromosomes are to be found in the marsupials, many of which have a small number of large chromosomes. Most other mammals on the other hand, have a large number of small chromosomes so that an accurate study is certainly a more difficult task than in many other organisms. But the extreme difficulties which have often been attributed to the study of mammalian chromosomes are also in part due to a lack of technique. This has led to confusion on even such matters as the chromosome number of a particular species (Sachs, I952b) and it now seems desirable to re-investigate much of the earlier work using more suitable techniques.

One of the many interesting points in mammals is that the animals have sex chromosomes which may be morphologically distinguished from the autosomes. These sex chromosomes are of importance both from a genetical and from a cytological point of view. Their genetical interest is connected with the existence of complete and partial sex linkage and their cytological interest is connected with their special behaviour during mitosis and meiosis. Some species of mammals show little or no size differences between the sex chromosomes and the autosomes. In these cases, therefore, identification of the sex chromosomes has not been possible at all the stages of division. But in Microtus agrestis, the short-tailed bank vole, the sex chromosomes are enormous and there is no difficulty in distinguishing them at mitosis and meiosis. An investigation of these giant sex chromosomes has been one of the purposes of the present study.

The existence of giant sex chromosomes in Swiss animals of $M$. agrestis had previously been reported by Matthey (1950) whose study was almost entirely based upon sectioned material. It has, however, now become possible, by the use of suitable squash techniques, to obtain much additional information not only on the sex chromosomes but also on general problems of chromosome behaviour and the sequence of meiosis. 


\section{MATERIAL AND TECHNIQUES}

The animals used in the present study were derived from two sources. Some were caught on the grounds of Bayfordbury, and others were obtained from Dr D. Chitty of Oxford. Animals from the two locations gave the same results.

The main technique was fixation in $1: 3$ acetic-alcohol followed by Feulgen staining and squashing (Sachs, 1952b) and this gave uniformly good results. In addition, fixation in aceto-carmine or acetic acid followed by the normal method of Feulgen staining, and fixation in $1: 3$ acetic-alcohol with a small amount of ferric chloride followed by aceto-carmine staining, also proved useful. As is shown by their own photographs, the staining procedures for mammalian testes recommended by Slizynski (1949) and Makino and Nishimura (1952) show no observable advantage over the normal method of making Feulgen squashes. This also applies to the section cutting method which is used by Matthey (1950).

\section{HETEROCHROMATIN AND THE SEX CHROMOSOMES}

The English animals of $M$. agrestis from Hertfordshire and Oxfordshire, like the Swiss animals studied by Matthey (I950) have a chromosome number of $2 n=50$. This number and the giant sex chromosomes thus appear to be characteristic for the species. The giant sex chromosomes can be easily identified in spermatogonial mitosis. The size of each chromosome, however, varies according to stage and fixation, so that it is useless to make absolute chromosome measurements. At mitotic metaphase, however, after acetic-alcohol fixation and Feulgen staining, the autosomes are about ${\mathrm{I}-2^{\mu}}^{\mu}$ long whereas the $\mathrm{X}$ chromosome is about $9^{\mu}$ and the $\mathrm{Y}$ chromosome about $6^{\mu}$ long (plate I, fig. 5).

Spermatogonial cells of the testes show that the sex chromosomes contain heterochromatin and this can be seen in some resting nuclei as two distinct chromocenters. But other resting nuclei, in different tissues, show no chromocenters. The detection of heterochromatin in the sex chromosomes by their appearance as chromocenters is thus not possible in all types of cells.

This presence or absence of chromocenters in the so-called resting nucleus is probably due to the different metabolic activities of the cells concerned. That the cytological appearance of heterochromatin can be modified by different metabolic activities of the cell was first found in studies on the effects of low temperature (Darlington and La Cour, 1938, I940, I94I ; La Cour 195I, et al.). This has shown that heterochromatin can, in certain species, show different differential behaviour under different environmental conditions. Heterochromatin which was intensely stained in resting nuclei could, after the effects of low temperature, be less intensely stained than the euchromatin at metaphase. Thus, as Darlington (1947) has pointed out, this behaviour of heterochromatin can be explained by the presence of genes which show allocycly under certain conditions. It can now be seen from the giant sex chromosomes that under some conditions the heterochromatin completely loses its differential stainability even in the resting nucleus. 
The allocyclic behaviour of heterochromatin, including the loss of differential stainability, can also be seen in the behaviour of the $\mathrm{X}$ chromosomes in some grasshoppers and crickets (White, 1940). In these insects the $\mathrm{X}$ chromosome shows what White calls " negative heteropycnosis" during the early spermatogonial divisions ; later it loses its differential stainability; and it becomes "positively heteropycnotic" during the prophase of meiosis. This behaviour of the $\mathrm{X}$ chromosome can also be related to the different appearance of heterochromatin under the differing conditions of the cells. Thus, in some cells, the heterochromatic genes react in the same way as the euchromatic genes and cannot be cytologically detected. In other cells, with the appropriate metabolic conditions, they can be detected by their differential metabolic cycle and a collection of such neighbouring genes can then be seen as distinct blocks of heterochromatin. So it is that, although some resting nuclei have no chromocenters, the appropriate conditions show that the $\mathrm{X}$ and the $\mathrm{Y}$ in $M$. agrestis contain heterochromatin.

\section{THE SEX CHROMOSOMES AT MITOSIS}

In spermatogonial cells the sex chromosomes at mitosis are, in relation to the autosomes, precocious during prophase and they lag during anaphase. But at mitotic metaphase both the sex chromosomes and the autosomes are arranged upon the spindle. During anaphase the $\mathrm{X}$ and the $\mathrm{Y}$ start to separate from the centromeres, but they are still held together when the autosomes have completely separated to the two poles (plate I, figs. 4 and 6). This slower separation of both $\mathrm{X}$ and $\mathrm{Y}$ may be in part due to the large size of these chromosomes moving in a restricted space. But it is more probably also due to the heterochromatin holding together the two chromatids.

In spermatogonial cells the spiral structure of the sex chromosomes is especially clear during the early prophase in the pre-meiotic mitoses. What appears to be an occasional case of somatic pairing, between a small segment of the $\mathrm{X}$ and a small segment of the $\mathrm{Y}$, has also been seen at this stage (plate I, fig. 2).

\section{TERMINAL CENTROMERES}

The mitotic cells in the ovary show that the female also have two enormous sex chromosomes, and that they both have submedian centromeres. The giant chromosomes with submedian centromeres are, therefore, the $\mathrm{X}$ chromosomes. The position of the centromere in the $\mathrm{X}$ and $\mathrm{Y}$ of the male has been most clearly seen at spermatogonial mitosis (plate I, figs. 3 and 5). The anaphase figures in these cells confirms that the $\mathrm{X}$ has a submedian centromere whereas the centromere of the $\mathrm{Y}$ appears to be terminal. Examination at mitotic metaphase again confirms the submedian centromere of the $\mathrm{X}$ but it also shows that the $\mathrm{Y}$ has, in addition to the long arm, a small 
structure at the centromere end of the chromosome. This does not, however, necessarily imply ( $c f$. White, 195I) that telocentrics in reality have a small second arm.

The existence of stable telocentrics, i.e. chromosomes with stable terminal centromeres, has often been doubted (Matthey, r95 $a$; White, 195I). This is partly due to the fact that the newly-formed telocentrics studies in plants such as Zea, Tulipa and Fritillaria, were found to be unstable. But this unstable condition does not apply to all telocentrics. Thus Darlington and La Cour (r950) have found that telocentrics in plants of Campanula may be unstable or stable, and that stable telocentrics can maintain themselves in nature. A further point which is often overlooked by those who doubt the existence of stable telocentrics, is that the centromere is not just a gap or a single point in the chromosome. The centromere is a multiple structure which can be broken at different places (Darlington, 1939). The functional telocentric will thus still possess at least some and probably all of this centromere structure so that the centromere end of the telocentric is not just an abrupt end to the chromosome arm. The existence of this centromere structure in telocentrics has in fact been seen in plants of Phleum (Ellerström and Tjio, r950). The Y in $M$. agrestis may also be a telocentric showing this centromere structure at metaphase. It can thus be concluded that stable telocentrics can exist, and their existence must be reckoned as a factor in chromosome evolution.

\section{A SEX VESICLE AT MEIOSIS}

An examination of testes containing cells at meiosis shows that the autosomes in many of the cells are at pachytene. A most striking first impression of these cells is that the nucleus contains, in addition to the pachytene autosomes, a large oblong body which is strongly Feulgen positive. Closer examination shows that this large Feulgen positive body consists of two Feulgen positive chromosomes, the $\mathrm{X}$ and the $\mathrm{Y}$, surrounded by a somewhat lighter stained vesicle (fig. IC, and plate II, fig. 4). Thus when the autosomes are at pachytene, the $\mathrm{X}$ and the $\mathrm{Y}$ are included in a special vesicle which can be designated as a sex vesicle. The existence of a sex vesicle surrounding the giant sex chromosomes in another species of Microtus has been reported by Muldal (1949).

The development of this sex vesicle in $M$. agrestis has already begun when the autosomes are at leptotene. At this stage the sex chromosomes are still separate, the $\mathrm{X}$ and the $\mathrm{Y}$ each forming what appears to be its own vesicle. The $\mathrm{X}$ and the $\mathrm{Y}$ then move together until they are included in the one large vesicle at pachytene (plate II, figs. I, 2 and 4). The vesicle surrounding the sex chromosomes still persists at diplotene (fig. IA and B) and diakinesis, but it has in most cases disappeared when the autosomes reach ist metaphase. The 
formation of this sex vesicle is characteristic of meiosis and it has never been seen at mitosis.

The sex chromosomes are thus inside their vesicle during those stages of meiosis where chiasmata are normally formed. This raises
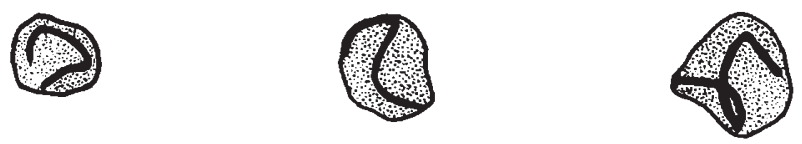

A

B

C
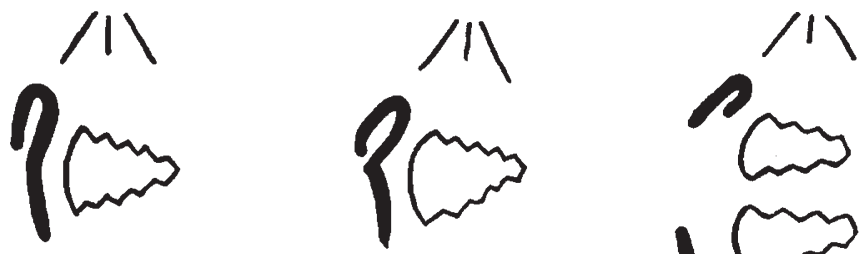

$11 /$

$11 /$

D
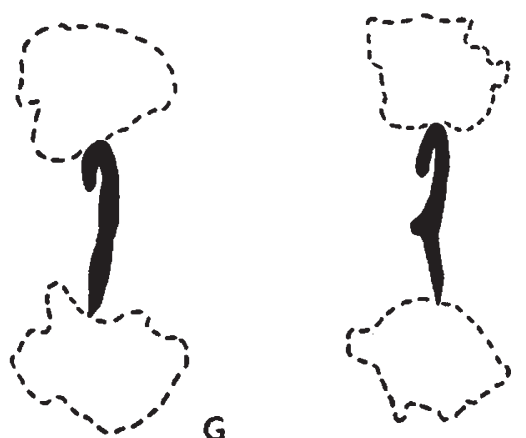

H

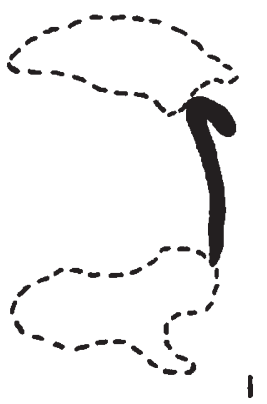

FIG. I

$A$ and $B$. The $\mathrm{X}$ and $\mathrm{Y}$ inside the sex vesicle $\times 2000$ at diplotene.

$C$. The $\mathrm{X}$ and $\mathrm{Y}$ inside the sex vesicle at pachytene.

$D$ and $E$. The $\mathrm{X}$ and $\mathrm{Y}$ connected at ist metaphase.

$F$. The $\mathrm{X}$ and $\mathrm{Y}$ not connected at early ist anaphase.

$G, H$ and $I$. The $\mathrm{X}$ and $\mathrm{Y}$ connected and lagging at late ist anaphase.

$\mathcal{N} . B$. - The arrangement of the sex chromosomes inside the sex vesicle is comparable to their arrangement when the sex vesicle has disappeared.

In $D, E$ and $F$ autosomes and spindle are drawn diagrammatically.

the question whether chiasma formation between the $\mathrm{X}$ and the $\mathrm{Y}$ in $M$. agrestis can and actually does take place. Matthey (I950), on the basis of his observations at Ist metaphase, at first concluded that chiasmata had been formed between the $\mathrm{X}$ and $\mathrm{Y}$ in $M$. agrestis. 
Later, however (1951 $a$ ), he concluded that this was doubtful. Both these opposing conclusions were based on the same set of observations. This confusion is probably caused by Matthey's own observations on what he supposed to be the meiotic development of the sex chromosomes before Ist metaphase. These had led him to conclude that the $\mathrm{X}$ and the $\mathrm{Y}$ flow together into a large homogeneous mass of material. He considers this meiotic development of the sex chromosomes as analogous to the fusion of two drops of mercury. The union of two masses of material to give one large homogeneous mass at pachytene thus seemed a contradiction to any normal pachytene pairing and chiasma formation between the sex chromosomes.

By the use of suitable techniques I find, however, that the early meiotic development of the sex chromosomes is not at all analogous to the fusion of two drops of mercury to form a homogeneous mass at pachytene. It can be seen in suitable preparations that the oblong Feulgen-positive body at pachytene is not a homogeneous structure, that it consists of two sex chromosomes inside a sex vesicle, and that there is no inherent contradiction between the early meiotic development of the sex chromosomes and the configurations seen at ist metaphase (fig. I).

\section{THE FORMATION OF CHIASMATA}

A study of pachytene shows that the $\mathrm{X}$ and $\mathrm{Y}$ are arranged in characteristic ways inside the sex vesicle. Owing to the faint differentiation between the materials of the sex chromosomes and of the vesicle, it is difficult to be sure of the exact mode of pairing. It appears, however, that $\mathrm{X}$ and $\mathrm{Y}$ are connected inside the vesicle end to end or by a small segment. This segment could be about the same size as the small somatically paired segment between the $\mathrm{X}$ and $\mathrm{Y}$ which is occasionally seen at the prophase of mitosis.

The $\mathrm{X}$ chromosome lies curved inside the vesicle at pachytene and diplotene and it maintains this curved shape at ist metaphase and even Ist anaphase. The $\mathrm{Y}$ which usually lies in a straighter position inside the vesicle also maintains its straighter position at Ist metaphase and anaphase. The sex vesicle often lies on one side of the nucleus and the sex chromosomes at ist metaphase are often on the edge of the plate.

The pachytene and ist metaphase configurations can both be explained by the existence of a small pairing segment between the $\mathrm{X}$ and the $\mathrm{Y}$. The configurations at Ist metaphase and Ist anaphase show that this pairing segment would be at the end furthest from the centromere in both chromosomes, and (as is to be expected) only reductional separation of the sex chromosomes occurs at ist anaphase.

The $\mathrm{X}$ and $\mathrm{Y}$ chromosomes are not always connected at ist metaphase and in these cells the sex chromosomes have presumably been unpaired. 
Darlington (1934) was the first to suggest a cytological explanation which could account for complete and incomplete sex linkage in mammals. This showed that both types of sex linkage could be explained by the existence of a pairing segment and a differential (non-pairing) segment in the $\mathrm{X}$ and the $\mathrm{Y}$. Genes on the differential segment would be completely sex-linked. Genes on the pairing segment would be partially sex-linked by the formation of chiasmata within the pairing segments. In the absence of any knowledge of the genetics of $M$. agrestis, nothing can be said about the presence or absence of incomplete sex-linkage in this animal. But from the cytological point of view the pachytene, ist metaphase and ist anaphase configurations can all be explained if the sex chromosomes have a small pairing and large differential segments. Chiasmata can then be formed within the pairing segment of the $\mathrm{X}$ and the $\mathrm{Y}$. Remnants of the sex vesicle may, however, still be present after diakinesis. This could conceal the chiasmata at ist metaphase and cause the sex chromosomes to lag at ist anaphase.

The presence of a sex vesicle during the prophase of meiosis which is so prominently seen in $M$. agrestis, is not a unique phenomenon restricted to this species. I have seen similarities to this type of meiosis in a number of other mammals. As genes for sex determination are presumably located on the sex chromosomes, the formation of a sex vesicle during the prophase of meiosis could have distinct evolutionary advantages. The sex vesicle prevents any possibility of crossing-over between the sex chromosomes and the autosomes which might otherwise arise owing to errors of pairing at pachytene. The sex vesicle could thus ensure that these sex-determining genes are always maintained on the sex chromosomes. This mechanism could then prevent the occurrence of gene combinations which might upset the normal balance for sex determination.

\section{ORIGIN OF THE GIANT CHROMOSOMES}

There is very little cytological data on the chromosomes of other species in the genus Microtus. Out of more than 200 different forms, only about half a dozen have been cytologically examined. Even among these there is some disagreement as to the chromosome number and the presence of giant sex chromosomes. It is, however, clear that species with higher chromosome numbers than $M$. agrestis have been found in Microtus and in the allied genus Clethrionomys. Thus $M$. nivalis (Matthey, 195 I $b$ ) and $C$. glareolus (Sachs, 1952b) both have $2 n=5^{6}$ and no giant sex chromosomes.

$M$. agrestis with $2 n=50$ and giant sex chromosomes could have originated from these or similar species with higher chromosome numbers. Thus in the plant Phyllospadix japonica, Harada (1944) reports that the female plants have 20 small chromosomes and the male plants have 15 small and one enormous chromosome. This 
large chromosome contains heterochromatin, is designated as the $\mathrm{Y}$ chromosome, and appears to have originated from the combination of 5 short chromosomes.

\section{LAMPBRUSH CHROMOSOMES AND THE SEQUENCE OF MEIOSIS}

Meiosis in the male of $M$. agrestis includes a modified form of what appears to be diplotene. At this stage the autosomes have a "woolly" outline with small protrusions connected to the chromosomes (plate II, fig. 3). This type of diplotene, described as diffuse diplotene, has been observed in a number of plants and animals (Darlington, I937). Its most extreme development has been found in animal oocytes, where the chromosomes are referred to as lampbrush chromosomes. There is a distinct similarity between these and what can be called the lampbrush chromosomes in $M$. agrestis. In $M$. agrestis the lampbrush structures begin to develop at pachytene and show their maximum development at what is apparently diplotene. In the animal oocytes there is also a maximum development of the lampbrush at what is apparently diplotene (Dodson, I948).

It can be shown that lampbrush development is associated with chemical changes in the chromosomes. For example, in the oocytes development of the lampbrush chromosomes is associated with a decrease in Feulgen staining. This decrease is associated with an increase in length of the chromosomes and in fully grown oocytes the chromosomes, except in a few small regions, are completely Feulgen negative (Serra, I947). The change from a Feulgen-positive to a Feulgen-negative chromosome associated with this extreme lampbrush development may be due $(a)$ to the increased growth of the chromosomes with the same amount of DNA (desoxyribose nucleic acid) decreasing the intensity of Feulgen staining and/or $(b)$ to the transfer of DNA from the chromosomes.

$R$ is (I95I) maintains the former explanation and denies the existence of DNA transfer from the chromosomes. There are, however, several lines of evidence which show that nucleic acid transfer does take place. Thus, the lampbrush development in $M$. agrestis is not associated with an increased size of the chromosomes. In this species the chromosomes at diplotene are if anything shorter than those at preceding stages of meiosis. The same applies to the lampbrush stages in grasshoppers (Srivastava, I 95I).

Evidence for the existence of nucleic acid transfer can also be obtained from studies on mitosis. Howard and Pelc (I95I) have concluded that DNA is synthesised during the resting stage in cells which are going to divide. Distinct Feulgen-positive chromosomes arc however only found at prophase, so that it is reasonable to assume that the DNA synthesised during the resting stage is transferred to the chromosomes at prophase. In the same way DNA can be trans- 
ferred from the chromosomes at telophase when the chromosomes lose their distinct Feulgen positive structure. The transfer of DNA to the chromosomes can also be inferred from results on the effects of low temperature (Darlington, i947).

Studies on RNA (ribose nucleic acid) have likewise shown the transfer of RNA to and from the chromosomes. Thus Jacobson and Webb (1952), who assume that nucleic acid in the cell always occurs in conjunction with a protein, conclude that ribonucleoprotein is transferred to the chromosomes during prophase and transferred from the chromosomes during anaphase. This latter process can be inferred by the presence of the transferred ribonucleoprotein between the two groups of anaphase chromosomes. These different lines of approach all show that nucleic acid transfer to and from the chromosomes can and does take place.

The synthetic processes of mitotic cells, such as protein synthesis, take place during the resting stage and it can be seen that they are preceded or associated with the transfer of nucleic acid from the chromosomes. Those stages of meiosis which show evidence of nucleic acid transfer from the chromosomes, as in the case in the formation of lampbrush chromosomes, are thus in this respect analogous to the synthetic part of the resting stage in mitosis. This analogy between lampbrush and resting stages can further be seen in the behaviour of heterochromatin. It has been shown that the sex chromosomes in $M$. agrestis contain heterochromatin which can be seen as chromocenters in some resting nuclei. These parts of the chromosomes therefore can maintain their DNA content even in these resting stages. In the same way the sex vesicle at diplotene, which contains the sex chromosomes, does not show the lampbrush formation which is shown by the autosomes: the heterochromatin during this stage of meiosis maintains its DNA content. The same differential behaviour of heterochromatin has thus been found both in resting stages of mitosis and in lampbrush stages of meiosis, and this also emphasises the similarity of these two stages. Lampbrush formation during certain stages of meiosis may thus be considered as a sign of synthetic processes inside the cell.

The existence of synthetic processes after chromosome pairing enables us to extend our knowledge of the sequence of meiosis. It has been shown in a number of organisms that the beginning of meiosis is connected with special circumstances. These include the supply of materials from tissues surrounding the germ cells, and the existence of special types of mitosis before meiosis. The supply of materials from tissues surrounding the germ cells (Darlington and La Cour, I946 ; Painter, I943; Montalenti et al., I950) includes the possibility of nucleic acid secretion associated with the beginning of meiosis. The direct evidence for special types of mitosis before meiosis comes from $M$. agrestis and some insects (White, I940) which show that meiosis is preceded by rapid mitotic cycles. In these 
insects it has been seen that there is almost no resting stage between the pre-meiotic mitoses. There is thus not a complete DNA transfer from the chromosomes during telophase so that the autosomes have an irregular outline at the beginning of the next prophase. This irregular outline is also found in the autosomes of $M$. agrestis, but it is not shown by the sex chromosomes which can maintain their DNA content even during resting stages. The special character of premeiotic mitoses can also be inferred from the existence of mitotic abnormalities which only occur before meiosis (Sachs, I952a).

The sequence of events leading up to meiosis can explain the presence of lampbrush chromosomes. It can reasonably be assumed that the rapidity of mitosis before meiosis excludes synthetic processes which would also be sufficient for chromosome reproduction during meiosis. The supply of substances from outside the germ cells may allow these cells to start on meiosis and proceed up to pachytene. Judging from the large proportion of cells at pachytene in the spermatocytes of $M$. agrestis, the cells remain at this stage for a long time. The continuation of meiosis is however dependent upon the synthesis of new chromosome material : this would take place after chromosome pairing and be made apparent by the lampbrush chromosomes.

The existence of this synthetic stage after chromosome pairing at meiosis allows us to understand one of the fundamental differences between mitosis and meiosis. This difference lies in the time of chromosome duplication (Darlington, 1937). Chromosome duplication at mitosis takes place at the resting stage and chromosome duplication at meiosis takes place after chromosome pairing at pachytene. It can now be seen that the resting stage of mitosis and these lampbrush stages after pairing at meiosis can both be considered as stages for the synthesis of chromosome material. The differences in the times of chromosome reproduction at mitosis and meiosis may thus be due to the differences in the time of synthesis of chromosome material.

\section{SUMMARY}

I. The rodent Microtus agrestis, with $2 n=50$, has enormous sex chromosomes which can be easily identified at mitosis and meiosis. The males have an X Y sex mechanism.

2. Both $\mathrm{X}$ and $\mathrm{Y}$ contain (or entirely consist of) heterochromatin which appear as chromocenters in some cells. This variation in the appearance of heterochromatin is probably due to different metabolic activities in the different cells.

3. At spermatogonial mitosis the sex chromosomes are precocious during prophase and lag during anaphase. There is occasional somatic pairing at mitotic prophase between small almost terminal segments of $\mathrm{X}$ and $\mathrm{Y}$.

4. The $\mathrm{X}$ and $\mathrm{Y}$ are separate at the beginning of meiosis and are included in a special sex vesicle by pachytene. The arrangements 


\section{Plate I}

Microphotographs of mitosis in the testes of Microtus agrestis. Feulgen $\times 3000$.

Fig. 1.-Early Prophase. Early development of the $\mathrm{X}$ and $\mathrm{Y}$.

Fig. 2.- Later prophase. Somatic pairing between a small segment of the $\mathrm{X}$ and $\mathrm{Y}$.

FiGs. 3 and 5.-Metaphase.

FiG. 4.--Early anaphase. $\mathrm{X}$ and $\mathrm{Y}$ beginning to separate.

FIG. 6.-Late anaphase. Delayed separation of the $\mathrm{X}$ and $\mathrm{Y}$. 


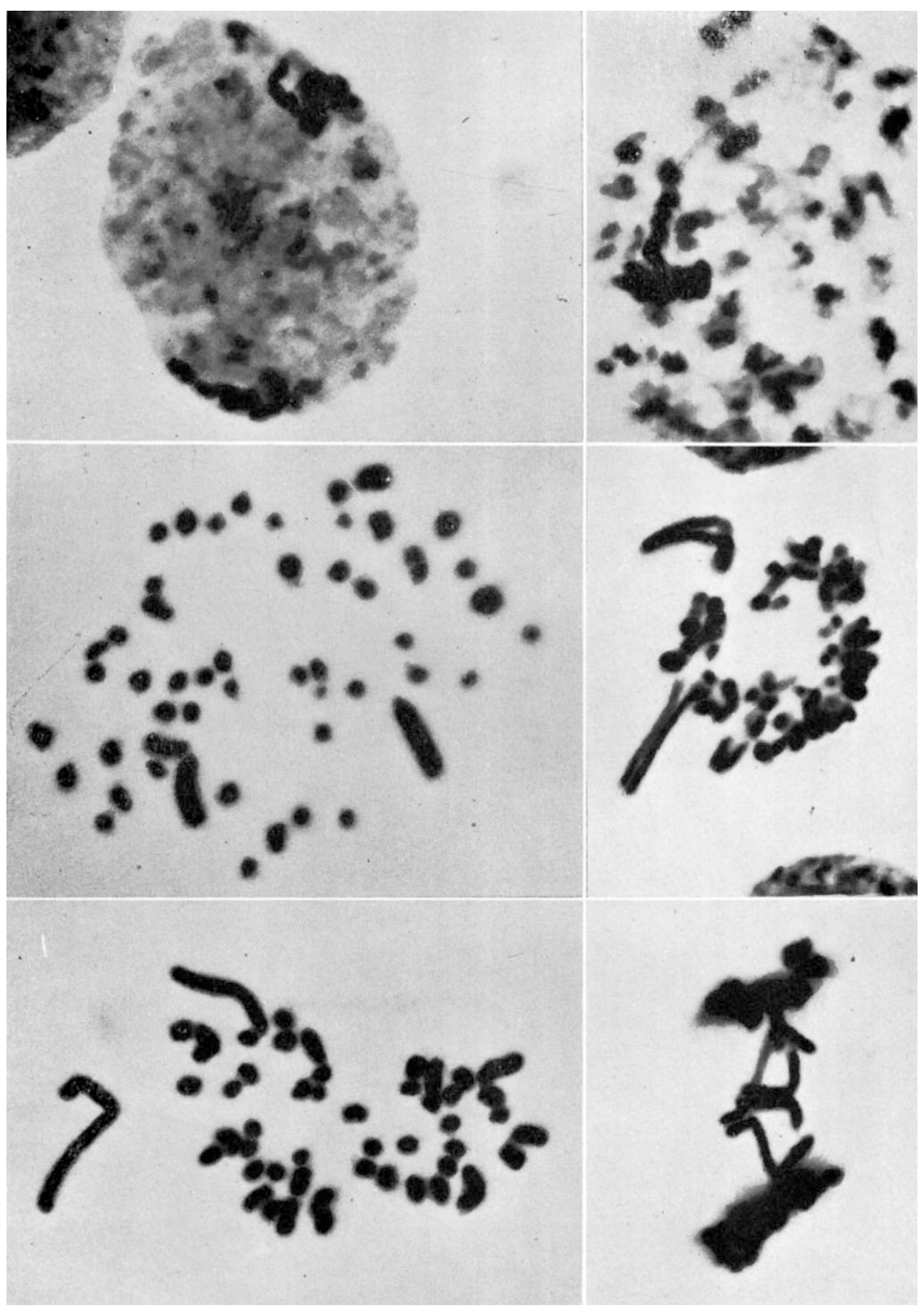




\section{Plate II}

Microphotographs of meiosis in the testes of Microtus agrestis. Feulgen $\times 2000$.

Fig. 1.-Stages in the development of the sex vesicle. The $X$ and $Y$ still separate (left hand cell); lying next to one another (centre); nearly included in the one sex vesicle (right hand cell).

Frg. 2.-Sex vesicle at pachytene. Unsquashed nucleus.

FIG. 3.--Sex vesicle at diplotene. Lampbrush autosomes.

Frg. 4.-Sex vesicle at pachytene. Squashed nucleus.

FIG. 5.-Early anaphase I. Curved arrangement of the $\mathrm{X}$ and straighter position of the $\mathrm{Y}$.

FIG. 6.-Iate anaphase I. Lagging of $\mathrm{X}$ and $\mathrm{Y}$. 





of the sex chromosomes inside the sex vesicle are comparable to their arrangement at ist metaphase when the vesicle has usually disappeared.

5. The configurations of the sex chromosomes from pachytene to Ist anaphase can be explained by the existence of a small pairing and large differential segments. The pairing segments in both $\mathrm{X}$ and $\mathrm{Y}$ would then be at the ends furthest from the centromere.

6. M. agrestis and its giant sex chromosomes could have originated from related species with higher chromosome numbers and no giant sex chromosomes.

7. Meiosis in the male $M$. agrestis includes stages with lampbrush chromosomes showing similarities to resting stages between mitoses. The development of lampbrush chromosomes at meiosis is interpreted as a sign of synthesis of chromosome material. Differences in the time of chromosome duplication at mitosis and meiosis can thus be explained by differences in the time of synthesis of chromosome material.

\section{REFERENCES}

DARLington, C. D. 1934. Anomolous chromosome pairing in the male Drosophila psuedo-obscura. Genetics, 19, 95-I 18.

DARlington, C. D. 1937. Recent Advances in Cytology, 2nd Ed. London : Churchill. DARlington, C. D. I939. Misdivision and genetics of the centromere. 7. Genet., $37,34 \mathrm{I}-364$.

Darlington, c. D. 1947. Nucleic acid and the chr נmosomes. Symp. Soc. Exp. Biol., $1,252-269$.

DARlington, C. D., AND LA COUR, L. F. I938. Diffe.ential reactivity of the chromosomes. Ann. Bot. Lond., N.S., 2, 61 5-625.

DARLINGTON, C. D., AND LA COUR, L. F. I940. Nucleic acid starvation of chromosomes in Trillium. 7. Genet., 40, 185-2 13.

DARLINGton, C. D., AND LA COUR, L. F. I94 I. The detection of inert genes. $\mathcal{F}$. Hered., 32, II 5-1 2 I.

DARLINGTON, C. D., AND LA COUR. 1946. Nucleic acid and the beginning of meiosis. Nature, 157,875 .

DARlington, C. D., AND LA COUR, L. F. 1950. Hybridity selection in Campanula. Heredity, 4, 21 7-248.

DODson, E. O. I948. A morphological and biochemical study of lampbrush chromosomes of vertebrates. Univ. California Publ. Zool., 53, 28I-314.

ellerström, S., AND tJí, J. H. I950. Note on the chromosomes of Phleum echinatum. Bot. Notiser, r95o, pp. 463-465.

harada, I. 1944. A sex chromosome of Phyllospadix. Fap. Four. Genet., 20, I27-1 28. HOWARD, A., AND PELC, S. R. I $95 \mathrm{I}$. Nuclear incorporation of $\mathrm{P}^{32}$ as demonstrated by autoradiographs. Exp. Cell. Res., 2, I 78-187.

JACOBSON, W., AND WEBB, M. 1952. The two types of nucleoprotein during mitosis. Exp. Cell. Res., 3, 163-183.

LA COUR, L. F. I951. Heterochromatin and the organisation of nucleoli in plants. Heredity, 5, 37-50.

MAKINO, S. AND NISHIMURA, I. 1952. Water pre-treatment squash technique. Stain Tech., 27, I-7.

matthey, R. 1950. Les chromosomes sexuels géants de Microtus agrestis L. La Cellule, 53, I63-184.

matthey, R. I951a. The chromosomes of the vertebrates. Adv. Genet., 4, I59-180. 
MATthey, R. I95 $\mathrm{I} b$. La formule chromosomique de Microtus orcadensis Millais. Remarques méthodologiques et discussion critique. Rev. Suisse Zool., 58, $201-213$.

MONTALENTI, G. et al. 1950. The supply of ribonucleic acid to the male germ cells during meiosis in Asellus aquaticus. Heredity, 4, 75-87.

MULDAL, s. I949. 40th Ann. Report John Innes Hort. Inst.

PAINTER, T. S. 1943. Cell growth and nucleic acids in the pollen of Rhoo discolor. Bot. Gaz., 105, 58-68.

RIS, H. I95I. Recent work on the chemistry of chromosomes. Symp. Cytol., pp. $2 \mathrm{I}-36$.

SACHS, Leo. 1952a. Chromosome mosaics in experimental amphiploids in the Triticina. Heredity, 6, I57-1 70.

SACHS, LEO. 1952b. Polyploid evolution and mammalian chromosomes. Heredity, $6,357-364$.

SERRA, J. A. 1947. Composition of chromonemata and matrix and the role of nucleoproteins in mitosis and meiosis. Cold Spring Symp. Quart. Biol., 12. 192-2 10.

SLIZYNSKI, B. M. 1949. A preliminary pachytene chromosome map of the house mouse. 7. Genet., 49, 242-245.

SRIVASTAVA, M. D. L. I951. "Lampbrush" fibres in the chromosomes of Chrotogonus incertus Bolivar. Nature, $167,775-776$.

WHITE, M. J. D. 1940. The heteropycnosis of sex chromosomes and its interpretation in terms of spiral structure. 7. Genet., 40, 67-82.

White, M. J. D. 1949. Chromosomes of the vertebrates. Evolution, 3, 379-38 r.

WHITE, M. J. D. 195I. Cytogenetics of orthopteroid insects. Adv. Genet., 4, I59-180. 